\title{
Systemic arterial supply to the lungs in pulmonary atresia and its relation to pulmonary artery development
}

\author{
Keith Jefferson, Simon Rees, and Jane Somerville \\ From National Heart Hospital and Institute of Cardiology, London
}

The anatomy of the systemic arterial supply to the lungs is described in 30 patients with pulmonary atresia and ventricular septal defect. The pattern is variable but broadly falls into two types. Multiple small arteries with a widespread origin from the aorta and its branches are associated with full development of the central pulmonary arteries. Larger arteries, which are fewer in number, tend to be associated with failure of central pulmonary artery development. It is suggested that these two types have a different origin, and that neither type represents the true bronchial arteries. The therapeutic implications are discussed.

Pulmonary atresia is a developmental anomaly in which there is complete obstruction between the ventricular portion of the heart and the pulmonary arteries. When the atresia is associated with a ventricular septal defect, the degree of pulmonary artery development is variable, and a simple classification for clinical purposes has been suggested (Somerville, 1970) (Fig. I).

The arterial supply to the lungs is derived entirely from the systemic circulation and may consist of a persistent duct or systemic arteries which vary in size, shape, number, origin, and course. The purpose of this paper is to describe the anatomy as seen on angiography and at necropsy, and to relate the various patterns to pulmonary artery development and to accepted embryological and anatomical concepts.

\section{Material and methods}

A consecutive series of 30 patients with pulmonary atresia associated with a large ventricular septal defect has been studied. The ages ranged from 4 months to 16 years. Patients who had a functioning surgical shunt were excluded because this made the study of the natural collateral channels difficult. Each patient had a right ventricular angiocardiogram to confirm the diagnosis of pulmonary atresia and an ascending aortogram to demonstrate the blood supply to the lungs (Lamers and Bruins, 1958; Somerville, 1969). Five patients also had descending aortograms and two had selective arteriograms (Rees and Somerville, I969).

Received 28 June 197 I.
Good radiological display of the systemic arteries to the lungs was essential for inclusion in this study. Serial films of these arteries were observed and they were classified into two types 'small' and 'large'. 'Small' arteries were multiple, small, tortuous, and uncountable in number. The exact origin and course of these arteries were difficult to define owing to overlap, but sites of origin were widespread from all parts of the aorta

FI G. I Classification of pulmonary atresia based on the degree of development of the central pulmonary arteries (after Somerville, 1970). Type I, complete pulmonary artery development; Type 2, pulmonary trunk atretic. Right and left pulmonary arteries present, but they may be unconnected; Type 3, pulmonary trunk and one pulmonary artery atretic. In the lung without a pulmonary artery, the intrapulmonary arteries are perfused by systemic arteries; Type 4, absence of pulmonary trunk and both pulmonary arteries. Both lungs are perfused by systemic arteries.

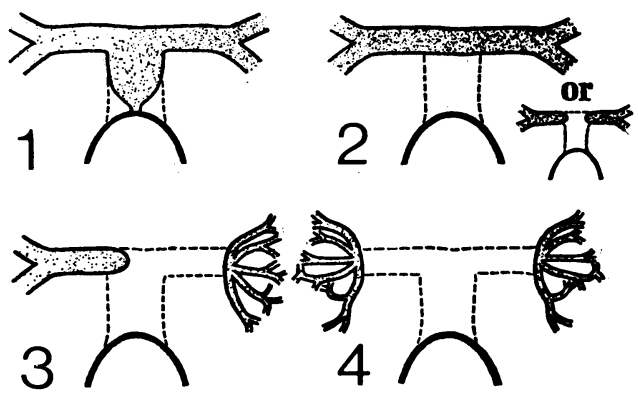


and its major branches (Fig. 2). 'Large' systemic arteries were wider, less tortuous, and countable, varying from $I$ to 5 in number, and 3 to $20 \mathrm{~mm}$ in width. They usually arose from the descending aorta below the isthmus and less commonly from its major branches (Fig. 3). Pulmonary artery development was classified Type I-4 (Fig. I) in each patient.

FIG. 2 Case I. $a, b, c$, late frames of ascending aortogram showing 'small' type systemic arteries with late filling of pulmonary arteries. $d$. Necropsy injection of descending aorta with barium sulphate suspension showing small type systemic arteries joining hilar -arteries on right side. Pulmonary artery filled on left side.
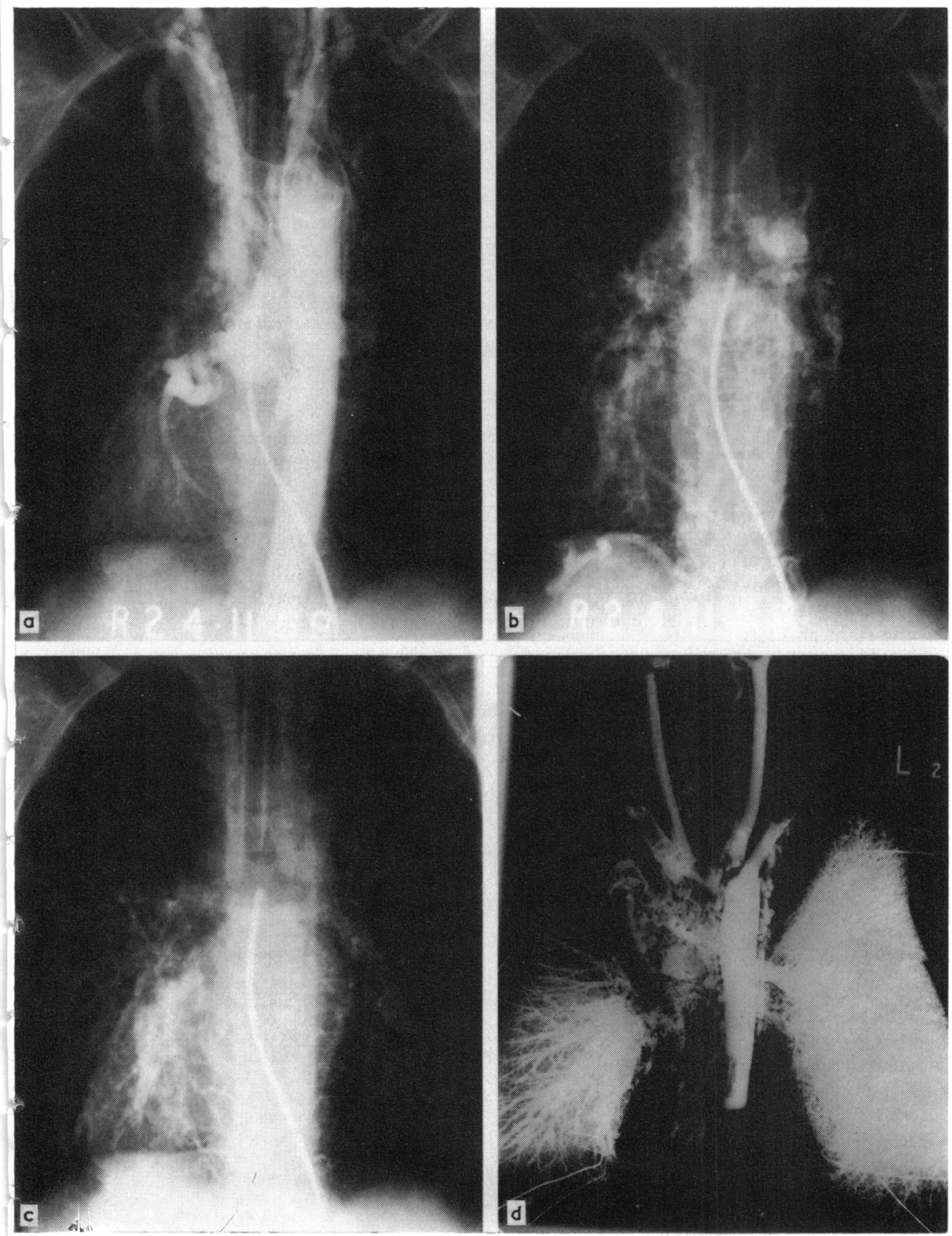


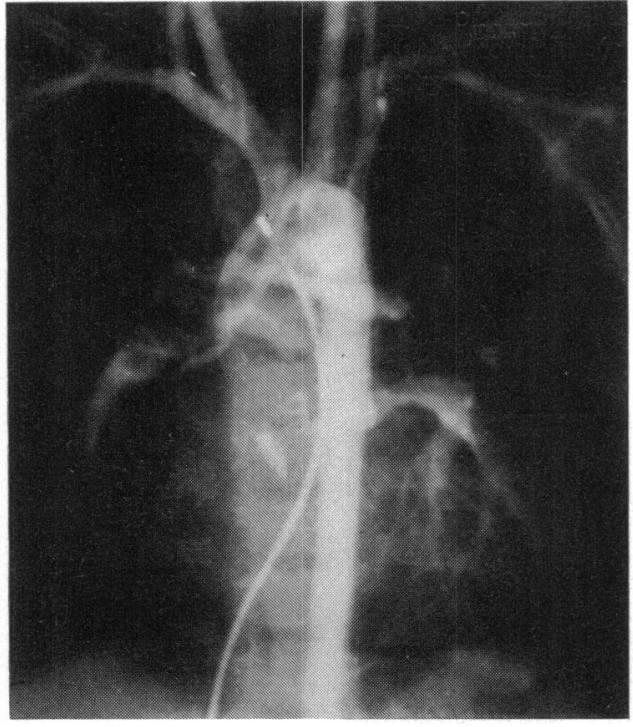

FIG. 3 Case 6. Ascending aortogram showing 'large' type systemic arteries joining directly with hilar arteries. Normal branching pattern in lungs. Long stenosis of branch from aortic arch.

\section{Embryology and terminology}

Available information on normal mammalian embryology (Huntington, 1919; Congdon, 1922; Tobin, 1952) indicates that the proximal parts of the sixth arterial arches, which connect the truncus arteriosus medially to the dorsal aortae laterally, form the right and left pulmonary arteries at about the fifth week and join up with the vascular spaces (pulmonary plexus) in the primitive lung buds. The pulmonary plexus also has connexions with the dorsal aortae through the intersegmental arteries (systemic arteries) which are present before sixth arch development (Fig. 4) but which disappear to be followed later at about the ninth week by the development of the 'bronchial arteries' (Boyden, 1970). The connexion of the central pulmonary arteries to the left dorsal aorta is maintained through the ductus arteriosus which forms from the distal part of the left sixth arch; this normally closes shortly after birth. The distal right sixth arch and the right dorsal aorta distal to the origin of the right subclavian disappear at about the seventh week (Fig. 5).

The terminology used in this paper is set out in Table I, together with the probable embryological equivalents. The term 'bronchial artery' is deliberately avoided, because systemic arteries entering the lungs in pul-

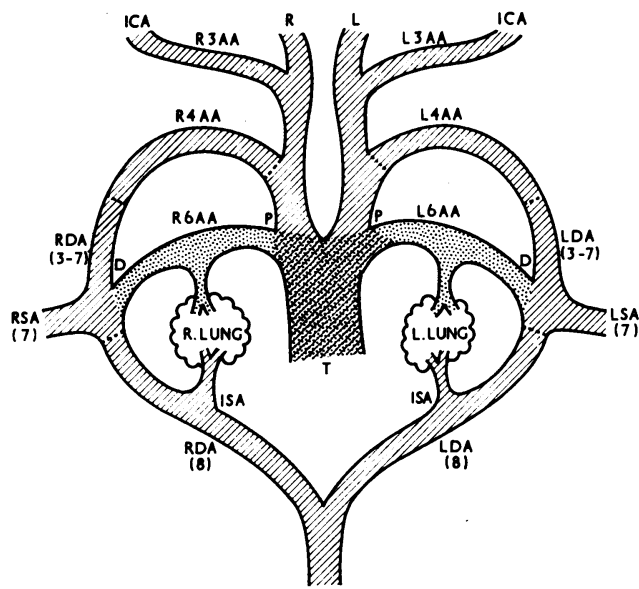

FIG. 4 Diagram to show vascular supply to the lungs from the sixth arterial arches and intersegmental arteries of the dorsal aortae (5th week). $R=$ right; $L=$ left; $D A=$ dorsal aorta; $P A=$ pulmonary artery; $I C A=$ internal carotid artery; 3-8 refer to somatic segments; $T=$ truncus arteriosus; $A A=$ arterial arch; $P=$ proximal; $D=$ distal $; I S A=$ intersegmental artery; $S A=$ subclavian artery.

monary atresia appear to have different anatomical features from the bronchial arteries in the normal adult.

\section{Results}

The type of systemic artery supplying the lungs in relation to the side of the aortic arch, development of the pulmonary arteries,

FIG. 5 Diagram to show disappearance of the intersegmental arteries (systemic plexus), the distal right sixth arch artery, and the right dorsal aorta (7th week).

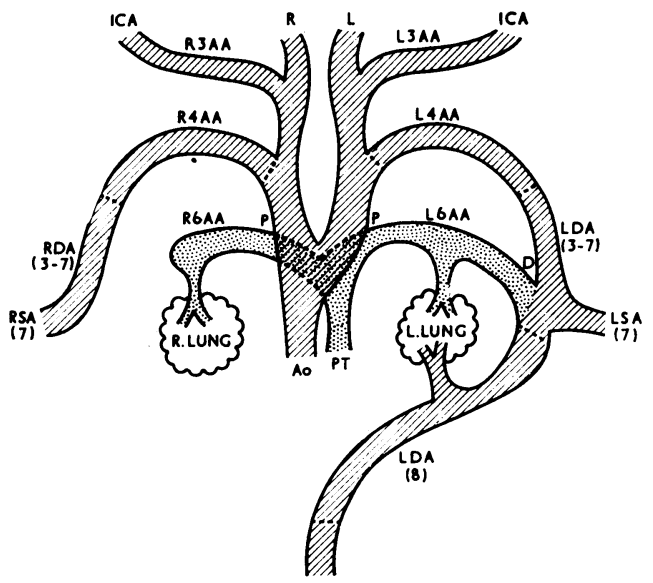


TABLE I Definition of terms with their embryological equivalents

\begin{tabular}{|c|c|c|}
\hline Term & Definition & Embryological equivalent \\
\hline $\begin{array}{l}\text { Pulmonary trunk (main } \\
\text { pulmonary artery) } \\
\text { Pulmonary artery }\end{array}$ & $\begin{array}{l}\text { Single vessel normally arising from right ventricle and } \\
\text { connecting with right and left pulmonary arteries } \\
\text { Artery resembling normal pulmonary artery in medi- } \\
\text { astinum connecting pulmonary trunk, if present, to hilar } \\
\text { arteries }\end{array}$ & $\begin{array}{l}\text { Part of truncus } \\
\text { arteriosus } \\
\text { Proximal sixth arterial } \\
\quad \text { arch }\end{array}$ \\
\hline Hilar arteries & Ist and 2 nd divisions of pulmonary artery & Pulmonary plexus \\
\hline Ductus arteriosus & $\begin{array}{l}\text { Short vessel connecting pulmonary artery to aortic arch } \\
\text { distal to subclavian artery and close to aortic isthmus }\end{array}$ & Distal sixth arterial arch \\
\hline Systemic arteries & $\begin{array}{l}\text { Any other vessel connecting aorta or branches to pulmon- } \\
\text { ary arteries at any level } \\
\text { (a) small type } \\
\text { (b) large type }\end{array}$ & See discussion \\
\hline
\end{tabular}

and the persistence of the duct are summarized in Table 2.

'Small' systemic arteries were found in 12 patients (Fig. 2). After an intramediastinal course, they appeared to join the pulmonary circulation at hilar level, filling the distal hilar arteries antegradely, and the right and left pulmonary arteries retrogradely when present. When small systemic arteries were the sole source of pulmonary flow to both lungs (Cases I, I4, I9, 24) or were associated with a persistent duct (Cases 4, 15, 27, 28) both pulmonary arteries were invariably present (Type I or 2 pulmonary atresia), and this was con. firmed at surgery or necropsy in all patients except one (Case 28).

In three patients the small arteries were unilateral. Small systemic arteries arising from the left subclavian and intercostal arteries supplied the distal left pulmonary artery in Case 4 (Fig. 6), who had had a left thoracotomy ro years earlier, and in an attempt to create a shunt the left pulmonary artery was kinked and occluded. Presumably this mass of collaterals supplying the distal left pulmonary artery were not present previously. The right lung was supplied by a small duct. In Cases 15 and 28 there were small systemic arteries on the right only, and a duct supplied the left pulmonary artery. The right pulmonary artery was at first thought to be absent, but in Case 15 examination of late films from the aortogram suggested the presence of a right pulmonary artery which was confirmed at thoracotomy. It is not known if a right pulmonary artery was present in Case 28, as thoracotomy was refused.

Large and small type arteries supplied the 'lungs in 4 patients (Cases $16,17,23,29$ ) in whom pulmonary artery development was less complete, being Type 4 in Case 16, Type 3 in Case 23, Type 2 or possibly 3 in Case 17, and Type $I$ in Case 29.
'Large' systemic arteries were seen in 15 patients, of whom 4 had small arteries as well, as mentioned above. Large arteries were from 3 to $20 \mathrm{~mm}$ wide, were less tortuous, and did not exceed five in number. They were easily identifiable as being different from the small systemic arteries. They usually arose from the descending aorta, and occasionally from the aortic arch or from one of its branches (Tynan and Gleeson, 1966). In contrast to

FIG. 6 Case 4. (a) Ascending aortogram showing small ductus connected to right pulmonary artery. Multiple small arteries in left mediastinum. (b) Late frame showing delayed filling of left pulmonary artery via small arteries. Lack of connexion of this vessel with its fellow was due to kinking as a result of a previous thoracotomy and attempted shunt procedure.

$\boldsymbol{a}$ $b$
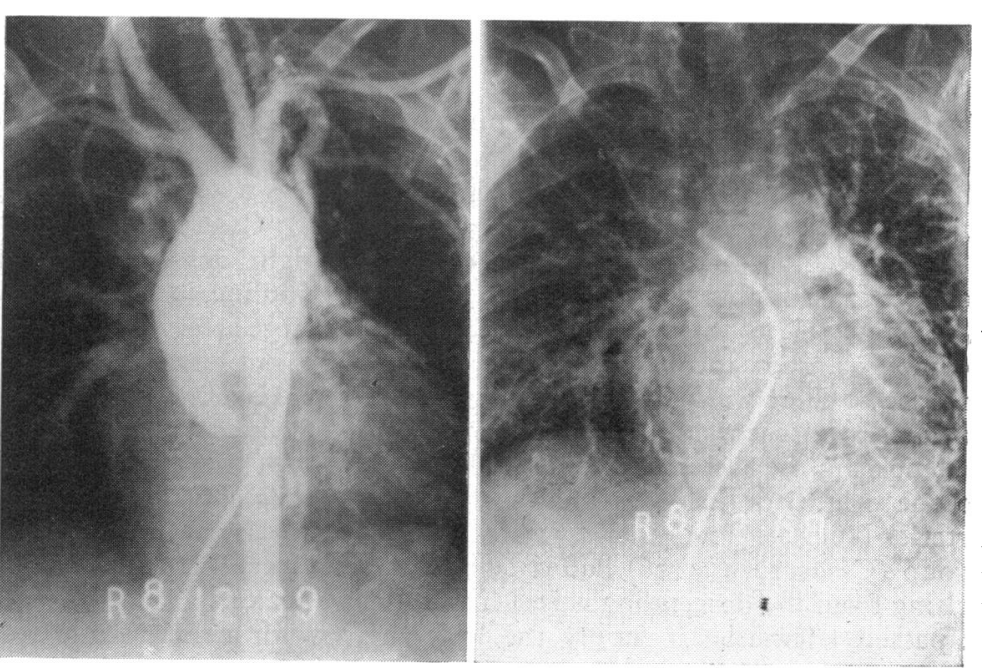
TABLE 2 Summary of type of systemic arteries related to type of pulmonary atresia, side of aortic arch, and patency of ductus arteriosus

\begin{tabular}{|c|c|c|c|c|c|c|c|}
\hline \multirow{2}{*}{$\begin{array}{l}\text { Case } \\
\text { No. }\end{array}$} & \multicolumn{2}{|l|}{ Systemic arteries } & \multirow{2}{*}{$\begin{array}{l}\text { Persistent } \\
\text { ductus }\end{array}$} & \multirow[t]{2}{*}{ Aortic arch } & \multirow{2}{*}{$\begin{array}{l}\text { Right pulmonary } \\
\text { artery }\end{array}$} & \multirow{2}{*}{$\begin{array}{l}\text { Left pulmonary } \\
\text { artery }\end{array}$} & \multirow{2}{*}{$\begin{array}{l}\text { Pulmonary } \\
\text { atresia } \\
\text { Type I-4 }\end{array}$} \\
\hline & Right & Left & & & & & \\
\hline I & Small & Small & - & Left & + & + & $\mathbf{I}$ \\
\hline 2 & $\begin{array}{l}\text { Large with proximal } \\
\text { stenosis }\end{array}$ & - & + & Left & - & + & 3 \\
\hline 3 & $\begin{array}{l}\text { Large with proximal } \\
\text { stenosis }\end{array}$ & Large & - & Left & + Incomplete & + Incomplete & 4 \\
\hline 4 & - & Small & + to right & Left & + & $\begin{array}{l}+ \text { blocked, } \\
\text { incomplete }\end{array}$ & $\mathbf{r}$ \\
\hline 5 & - & - & + & Left & + & + & I \\
\hline 6 & $\begin{array}{l}\text { Large with proximal } \\
\text { stenosis }\end{array}$ & $\begin{array}{l}\text { Large with proximal } \\
\text { stenosis }\end{array}$ & - & Left & - & - & 4 \\
\hline 7 & Large & Large & ? to left & Right & - & - & 4 \\
\hline 8 & - & $=$ & + & Left & + & + & 1 or 2 \\
\hline 9 & $\begin{array}{l}\text { Large with proximal } \\
\text { stenosis }\end{array}$ & $\begin{array}{l}\text { Large with proximal } \\
\text { stenosis }\end{array}$ & - & Right & - & - & 4 \\
\hline 10 & $\begin{array}{l}\text { Large with proximal } \\
\text { stenosis }\end{array}$ & $\begin{array}{l}\text { Large with proximal } \\
\text { stenosis }\end{array}$ & - & Right & - & - & 4 \\
\hline II & - & - & + & Left & + & + & $\mathbf{I}$ \\
\hline 12 & Large & Large & - & Left & $?$ & ? & 2 \\
\hline 13 & Large & Large & + & Left & + & + & 2 \\
\hline 14 & Small & Small & - & Right & + & + & 2 \\
\hline 15 & Small & - & + to left & Left & + & + & 2 \\
\hline 16 & $\begin{array}{l}\text { Large with proximal } \\
\text { stenosis }\end{array}$ & Large & - & Right & - & - & 4 \\
\hline 17 & Small & $\begin{array}{l}\text { Large with proximal } \\
\text { stenosis, small }\end{array}$ & - & Left & + & + Incomplete & 3 \\
\hline 18 & $\begin{array}{l}\text { Large with proximal } \\
\text { stenosis }\end{array}$ & $\begin{array}{l}\text { Large with proximal } \\
\text { stenosis }\end{array}$ & - & Left & - & - & 4 \\
\hline 19 & Small & Small & - & Right + left & + & + & 2 \\
\hline 20 & $\begin{array}{l}\text { Large with proximal } \\
\text { stenosis }\end{array}$ & $\begin{array}{l}\text { Large with proximal } \\
\text { stenosis }\end{array}$ & - & Left & $?$ & $?$ & ?4 \\
\hline 21 & - & - & + & Left & + & + & $\mathbf{I}$ \\
\hline 22 & - & - & + & Left & + & + & I \\
\hline 23 & $\begin{array}{l}\text { Small, large with } \\
\text { proximal stenosis }\end{array}$ & $\begin{array}{l}\text { Large with proximal } \\
\text { stenosis }\end{array}$ & - & Left & + Incomplete & + Incomplete & 3 \\
\hline 24 & Small & Small & - & Left & + & + & 2 \\
\hline 25 & - & - & + & Left & + & + & $\mathbf{I}$ \\
\hline 26 & Large & Large & - & Right & ? & ? & 2 \\
\hline 27 & Small & Small & + & Right & + & + & I \\
\hline 28 & Small & - & + to left & Left & + & + & 2 \\
\hline 29 & Small & Small & - & Right & + & + & I \\
\hline 30 & - & - & + & Left & + & + & $\mathbf{I}$ \\
\hline
\end{tabular}

$+=$ present $;-=$ absent .

the small arteries which joined the pulmonary artery at an angle, the large arteries entered the hilum and became directly continuous with the hilar arteries.

In 8 patients, these large arteries were the sole systemic supply to the lungs; in 6 (Cases $3,6,9,10,18,20)$ there was no certain central pulmonary artery formation (Type 4), though in Case 20 there was possibly a small pulmonary artery on each side. In these 6 there was a stenosis in the systemic arteries, either close to the origin, or just proximal to the hilar arteries (Fig. 7). The other 2 patients in this group (Cases 12 and 26) had a large artery arising from the descending aorta. In Case I2 it passed leftwards to supply the left lung, turning to cross the midline to branch and supply the right lung, but in addition there was a separate artery to the right lung (Fig. 8); Case 26 had a single artery arising from a right descending aorta, coursing across the midline to supply both lungs. Whether this large artery represents the pulmonary arteries is not known, but is discussed below.

Cases 2, 7, and 13 had large systemic arteries with a ductus. Case 2 was an example of Type 3 since the ductus supplied the left lung and the right lung was supplied entirely by 'large' type arteries, the right pulmonary artery being absent. This was confirmed at necropsy (Fig. 9). Case 7 had a left ductus with a right aortic arch. The right lung was 
supplied by a large systemic artery arising from the descending aorta. The pulmonary arteries were absent (Type 4) (Fig. 10). Case I3 had a full set of pulmonary arteries supplied by a ductus (Type I), but two single separate systemic arteries arose from the descending aorta to supply part of the right upper and left lower lobes, respectively. The territory perfused by these vessels was quite separate from the rest of the lungs. Necropsy confirmed this, and it was also shown that the small arteries in the territory supplied by the systemic arteries had changes of severe pulmonary hypertension, whereas the histology of the arteries in the rest of the lungs was normal (Fig. II).

Ductus arteriosus The ductus arteriosus was patent in 14 patients, connected to both pulmonary arteries in 10, and to one side only in 4. In 7 patients (Cases 5, 8, II, 21, 22, 25,30 ) the ductus was the sole source of blood supply to the lungs with no visible systemic arteries. All patients in this group had full development of the pulmonary arteries (Type I or 2). Of the other 7, 3 had large systemic arteries as well (Cases 2, 7, 13) and 4 had small arteries (Cases 4, 15, 27, 28).

Aortic arch Eight patients had a right aortic arch, 2 I had a left arch, and I had a double arch. All patients with a ductus had a left arch except Case 7, who had a left ductus and a right arch (Fig. 10). Six out of the 15 patients with large systemic arteries had a right arch in contrast to 2 out of 8 with small
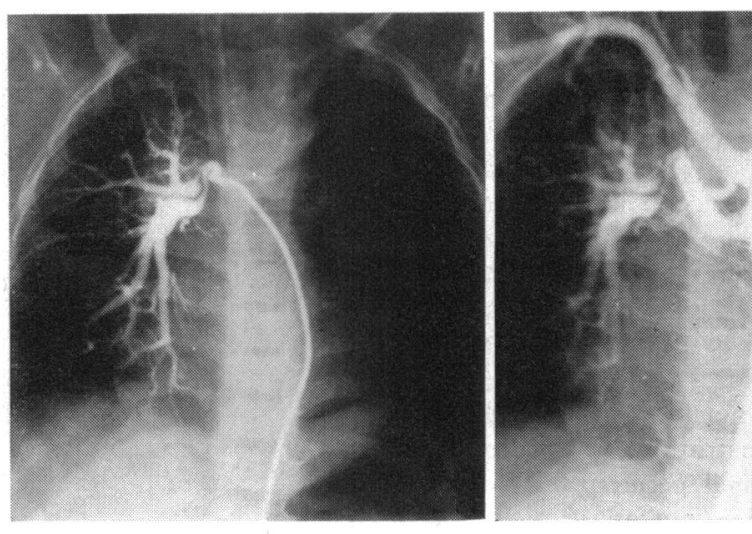

$a$

$b$

FIG. 7 Case 20. (a) Descending aortogram showing large systemic arteries arising from descending aorta directly continuous with hilar arteries. Pulmonary arteries absent. (b) Selective injection into large systemic artery to right lung showing stenosis at junction with hilar arteries. Intrapulmonary branching pattern normal.

arteries, though the patient with a double arch had small arteries on both sides.

\section{Discussion}

Successful surgical treatment of pulmonary atresia is dependent on central pulmonary artery development, as without this a shunt procedure or total correction is not at present possible (Ross and Somerville, I968).

FIG. 8 Case I2. (a) Descending aortogram showing two large arteries arising from aorta.

(b) Later frame showing pulmonary arteries filling from large left artery. All arteries are lung enlarged. Pulmonary hypertension. (c) Suggested relation of the left sided artery to arterial arch development. Tracing of left fourth aortic arch, left dorsal aorta, and sixth arch (cf. Fig. 4).
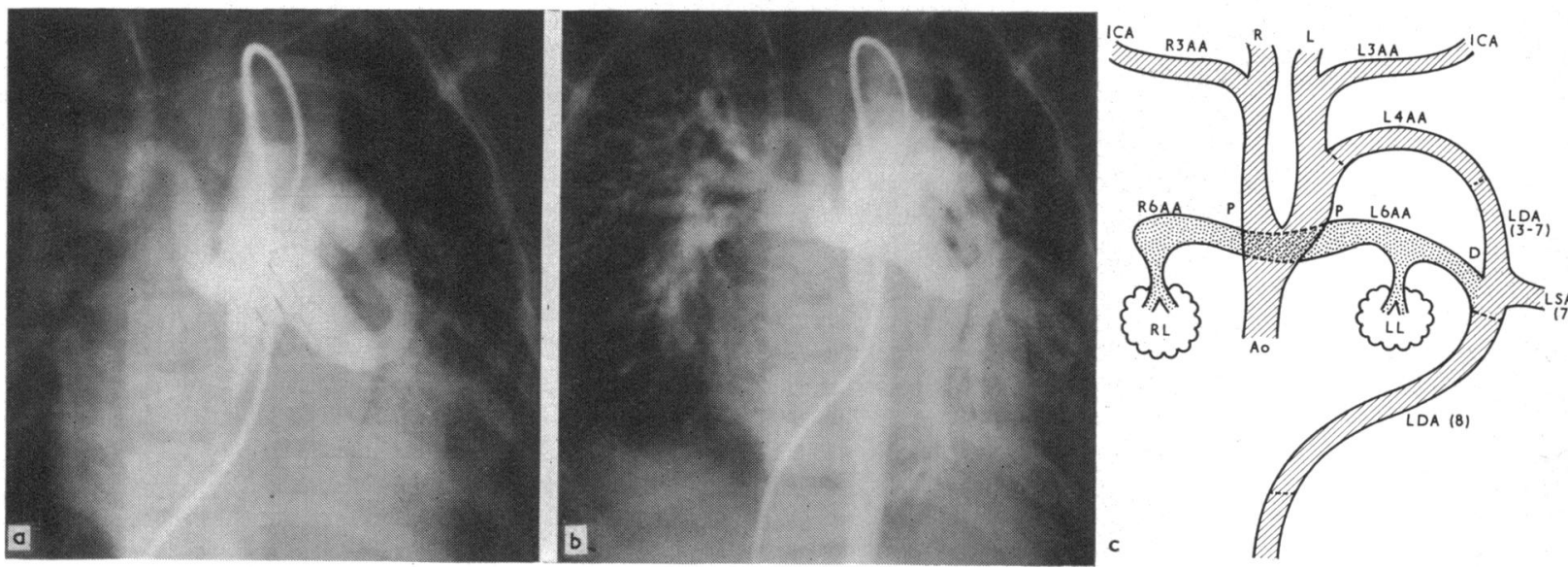
From this study it appears that there are two basically different types of systemic artery supplying the lungs, and that in general the pulmonary arteries are present with the 'small' type and absent with the 'large' type. The outlook for a patient with 'small' type arteries is, therefore, brighter, and it becomes extremely important to recognize this group by careful angiography. Filling of these small tortuous arteries with contrast medium injected into the aorta is often quite slow, and the lungs may not be opacified for several seconds. Demonstration of the central pulmonary arteries is dependent upon retrograde flow from the point of anastomosis between the systemic and pulmonary circulations in the hilum. At this stage the contrast is often poor and it is quite easy to miss a sizable vessel lying across the mediastinum. Three technical points are therefore important - first, to inject a large volume of contrast, up to 2 $\mathrm{ml} / \mathrm{kg}$ bodyweight; secondly, to use a biplane film changer as opposed to cine to obtain high quality radiographs; and thirdly, to set the programme so that filming is continued for a minimum of six seconds.

The association of pulmonary artery development and 'small' systemic arteries makes it tempting to postulate that they appear late in development, after the sixth arches have fully formed and connected to the lungs. It is also possible that they may be acquired in the sense that they do not represent persistence
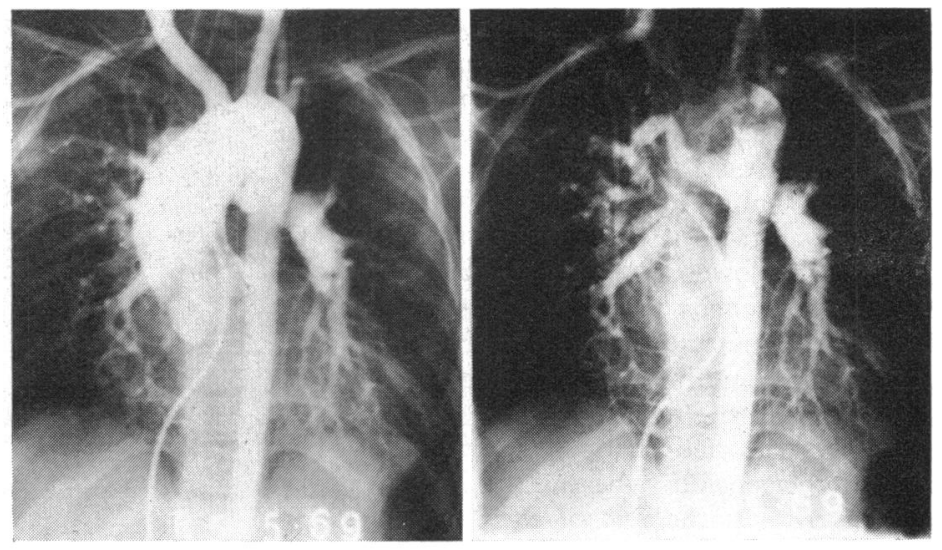

$a$

FIG. 9 Case 2. ( $a$ and $b$ ) Ascending aortogram showing left ductus. Right lung supplied by large type systemic arteries with stenoses.

of normal embryological structures which disappear before birth. Support for this theory is their great similarity in origin, course, and distribution to the arteries which appear after pulmonary artery thrombosis or in chronic lung disease, in which the acquired origin of the vessels is not in doubt (Cockett and Vass, 195I). The course of events in one patient, Case 4 (Fig. 6), also suggests that the small type arteries which were maintaining a blood

FI . Io Case 7. ( $a$ and $b$ ) Ascending aortogram showing artery to left lung arising from left innominate, presumably a left ductus. Right lung supplied by large artery arising from descending aorta. Aortic arch right-sided. (c) Suggested embryological development of right aortic arch and left ductus.
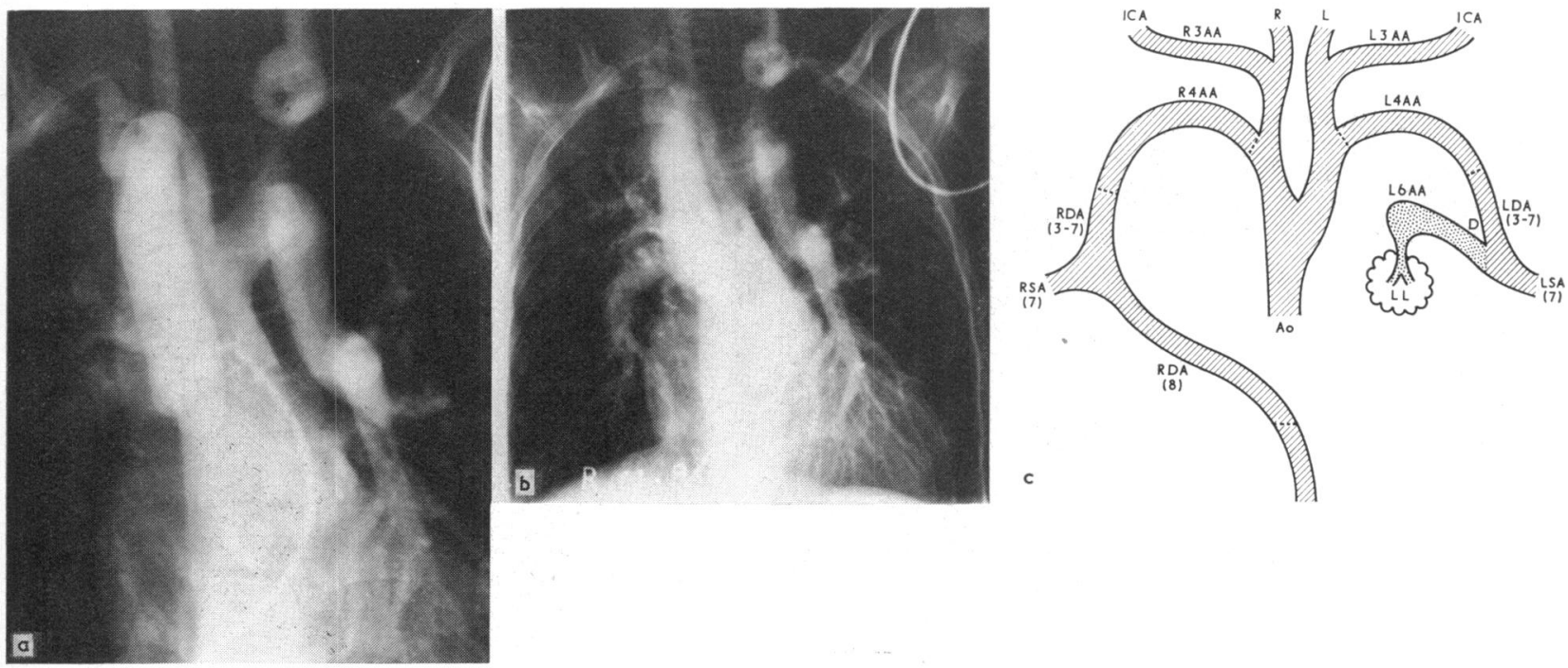
supply to the left lung were acquired, as the ductus was persistent but strangely connected to the right pulmonary artery, and the left pulmonary artery was said to be present at thoracotomy but probably thrombosed afterwards. Pulmonary atresia with full pulmonary artery development is no disadvantage in the fetus providing the ductus is patent, and it seems likely that many of these small type arteries may appear early in neonatal life when the ductus closes, a time when clinical deterioration is well documented.

In most patients with large type systemic arteries the pulmonary arteries are absent, and the systemic arteries run directly into the hilum to continue as hilar arteries with a normal intrapulmonary branching pattern. These arteries almost certainly have an embryological origin.

The lungs develop as outpouchings from the foregut, lying initially in the neck, but later migrating down into the thorax. Vascular spaces form within them, the so-called pulmonary plexus, and these are supplied by intersegmental branches of the dorsal aortae on each side. As the connexion of the pulmonary plexus to the sixth arterial arches is established, the systemic arteries disappear. According to Boyden (1970), they disappear completely, but failure of sixth arch develop-

FIG. II Case I3. (a) Arch aortogram showing ductus supplying both lungs, with separate arteries to the right and left lower lobes. (b) Selective angiogram of right upper lobe artery showing normal intrapulmonary branching and no proximal stenosis. (c) Selective angiogram of left lower apical segmental artery. (d) Necropsy injection specimen of left pulmonary artery. Normal pattern. (e) Necropsy injection specimen of left lower apical segmental artery showing deficient peripheral branching.
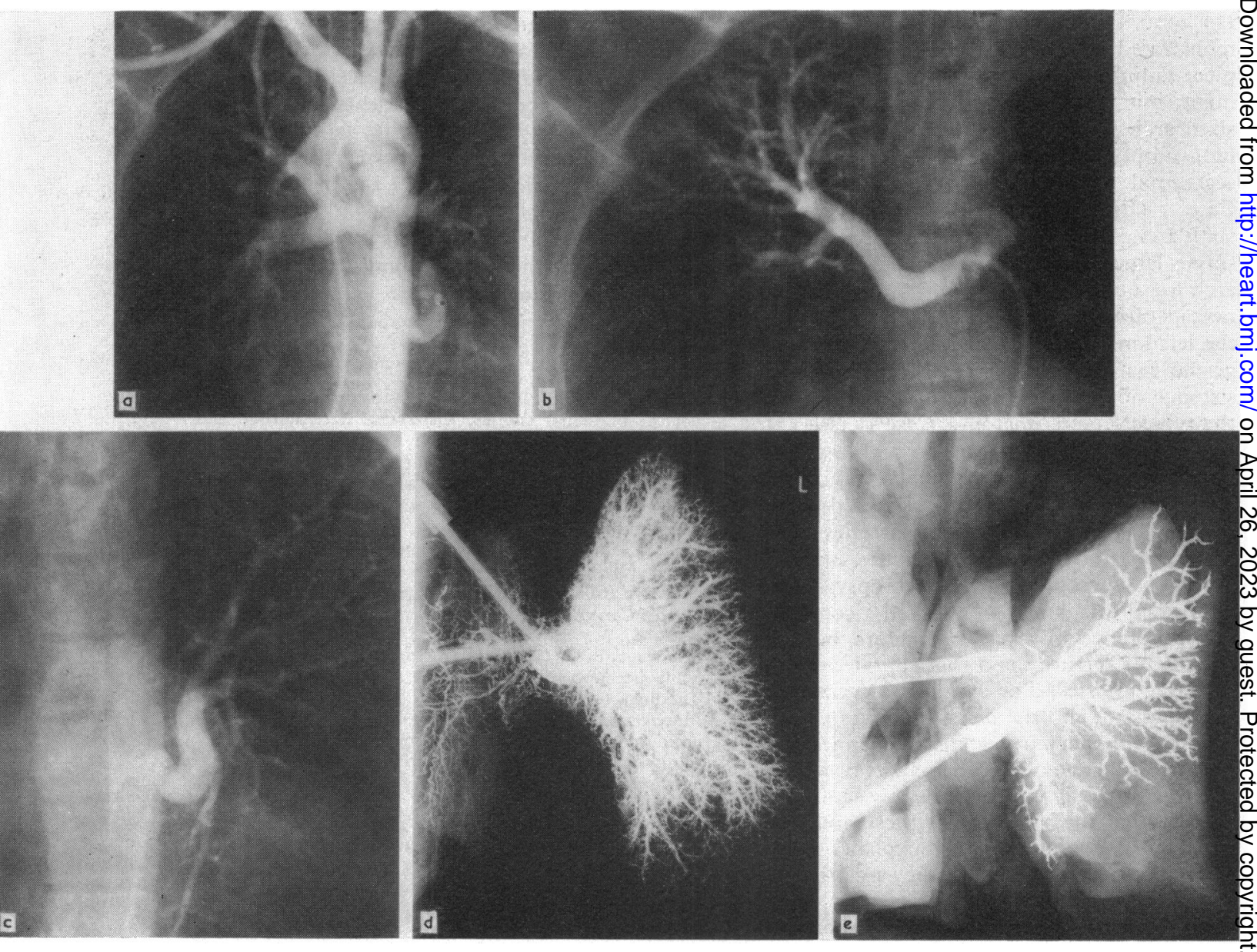
ment would logically result in persistence of these arteries in order to maintain a blood supply to the lungs. The suggestion is, therefore, that large type systemic arteries are truly congenital and represent persistence of the primitive intersegmental branches of the dorsal aortae which supply the lung bud.

If these assumptions about the origins of the systemic arteries are correct, then neither type has a common embryological origin, with the bronchial arteries of the normal adult. Though the bronchial arteries no doubt develop and may even be larger than normal in pulmonary atresia, we suggest that the term 'bronchial artery' should not be used to describe the systemic supply to the lungs in this disease.

Five patients in this series (Cases 2, 7, 12, 13, 26) had an unusual pattern of systemic supply to the lungs and they raise interesting embryological speculation. Case 2 (Fig. 9) had a ductus which arose in the usual place from a left aortic arch to connect with the left lung. The right lung was supplied by four 'large' type systemic arteries with stenoses. No central right pulmonary artery was demonstrated, so that the basic defect was complete failure of proximal sixth arch development, but with persistence of the distal left sixth arch to supply the left lung: the right lung supply remained via the primitive intersegmental branches of the dorsal aorta. Case 7 (Fig. ro) also had absent proximal sixth arches, but the lungs were supplied by a single large vessel on each side. The aortic arch was on the right. The right lung was connected directly to the descending aorta, and the left lung to the left innominate. It is suggested that both these vessels represent persistence of the distal sixth arch, but without the typical ductus anatomy. Case 13 (Fig. II) had a combination of a ductus and large systemic arteries. The ductus, which was narrow at its pulmonary end, was connected in the usual way to the pulmonary arteries. Two systemic arteries also entered the lungs to supply a separate territory. Necropsy studies confirmed this, and also revealed a conspicuous difference in arterial structure between the ductus territory and that supplied by the systemic arteries. The systemic arteries were not stenosed, and the distal branches showed severe pulmonary hypertensive changes. The narrow distal end of the ductus was protecting the rest of the lungs from the systemic pressure so that the histology of these areas was normal. The only possible explanation for these unusual arteries is that they are primitive systemic arteries of the large type which have, for some reason, persisted. A somewhat similar case was described by Hessel et al. (1970). In Cases I2 (Fig. 8) and 26, both lungs received all their blood via a very large vessel which arose from the mid-descending aorta. Having entered one hilum and given off branches to the lung, the vessel crossed the midline to supply the opposite lung. The central section of this artery had all the anatomical features of the right and left pulmonary arteries, and has been regarded as such. Whether or not its connexion to the aorta is via a derivation of the distal sixth arch is a matter of speculation, but the site of origin was much lower than the classical ductus arteriosus.

Despite the variable patterns of systemic artery, the arteries in the lung showed a normal branching pattern, suggesting that whatever their central connexions, the intrapulmonary arteries are always derived from the pulmonary plexus. The point of junction is identifiable as the level at which normal pulmonary arterial anatomy begins, but in many patients this point was marked by a narrowed segment of varying length. These stenoses are clearly of great haemodynamic significance, as they protect the lungs from systemic pressure, but at the same time may produce a lower than ideal pulmonary flow. Patients without stenoses in their systemic arteries had larger central pulmonary arteries, tapering down in the periphery, indicating severe and probably irreversible pulmonary hypertension, so that however favourable the anatomy might be for total correction, they would almost certainly be excluded on these grounds.

\section{References}

Boyden, E. A. (1970). The time lag in the development of the bronchial arteries. Anatomical Record, 166, 6II.

Cockett, F. B., and Vass, C. C. N. (195I). A comparison of the role of the bronchial arteries in bronchiectasis and in experimental ligation of the pulmonary artery. Thorax, 6, 268.

Congdon, E. D. (1922). Transformation of the aortic arch system during the development of the human embryo. Contributions to Embryology (Fublications of the Carnegie Instit tion), 14, 47 (No. 68).

Hessel, E. A., Boyden, E. A., Stamm, S. J., and Sauvage, L. R. (1970). High systemic origin of the sole artery to the basal segments of the left lung: findings, surgical treatment, and embryologic interpretation. Surgery, 67, 624 .

Huntington, G. S. (1919). The morphology of the pulmonary artery in the mammalia. Anatomical Record, 17, 165.

Lamers, J. J. H., and Bruins, C. (1958). Thoracic aortography in atresia of the pulmonary artery. Archivum chirurgicum Neerlandicum, 10, 386.

Rees, S., and Somerville, J. (I969). Aortography in Fallot's tetralogy and allied lesions. In Proceedings of the British Cardiac Society. British Heart fournal, 30, 423. 
Ross, D. N., and Somerville, J. (1968). Pulmonary atresia and its surgical correction. Vth European Congress of Cardiology, Athens.

Somerville, J. (1969). Angiocardiography in pulmonary atresia. Proceedings of the Association of European Paediatric Cardiologists, 5, 32.

Somerville, J. (1970). Management of pulmonary atresia. British Heart fournal, 32, 641.

Tobin, C. E. (1952). The bronchial arteries and their connections with other vessels in the human lung. Surgery, Gynecology and Obstetrics, 95, 741.

Tynan, M. J., and Gleeson, J. A. (I966). Pulmonary atresia with bronchial arteries arising from the subclavian arteries. British Heart fournal, 28, 573.

Requests for reprints to Dr. Simon Rees, Institute of Cardiology, 35 Wimpole Street, London WI M8EX.

\section{Notice}

The 'Fondation de Physiopathologie Professeur Lucien Dautrebande' will award an international prize of about 500,000 Belgian Francs ( $\$ 10,000$ U.S.) during the year 1973. It will be for work on human or animal physiopathology, the work preferably having therapeutic implications. For further information about this prize, please write to the office of the Foundation: 35, chaussée de Liège, 5200 Huy (Belgium). 